\title{
TANGGUNG JAWAB PUSKESMAS DALAM PEMELIHARAAN KESEHATAN MASYARAKAT PESANTREN DIHUBUNGKAN DENGAN UNDANG-UNDANG NOMOR 36 TAHUN 2009 TENTANG KESEHATAN DAN QANUN ACEH NOMOR 4 TAHUN 2010 TENTANG KESEHATAN (Studi Kasus Skabies di Kecamatan Kuta Alam Kota Banda Aceh)
}

\author{
Habibi \\ Magister Ilmu Hukum Pascasarjana Unisba \\ e-mail : camma192@yahoo.com
}

\begin{abstract}
Abstrak - Pembangunan kesehatan pada tingkat pertama di Kecamatan Kuta Alam Kota Banda Aceh dilaksanakan oleh puskesmas sesuai dengan Undang-Undang Nomor 36 Tahun 2009 Tentang Kesehatan dan Qanun Aceh Nomor 4 Tahun 2010 Tentang Kesehatan. Penelitian ini untuk mengetahui tanggung jawab dan implementasinya Puskesmas dalam Pemeliharaan Kesehatan Masyarakat Pesantren di Dayah Terpadu Inshafuddin Kecamatan Kuta Alam Kota Banda Aceh dihubungkan dengan Undang-undang dan Qanun. Penelitian ini menggunakan metode deskriptif analitis dengan pendekatan yuridis normatif. Hasil penelitian menunjukkan tanggung jawab Puskesmas dalam pemeliharaan kesehatan merupakan tanggung jawab institusional atau jabatan, dikarenakan tugas dan kewenangan yang dilaksanakan oleh puskesmas adalah amanat Undang-undang dan Qanun serta implementasi tanggung jawab Puskesmas dalam melaksanakan upaya promotif dan preventif belum berhasil memadukan berbagai upaya kesehatan termasuk upaya kuratif dan rehabilitatif belum ada kebijakan secara terperinci.
\end{abstract}

Kata kunci : Tanggung Jawab Hukum, Pemeliharaan Kesehatan, Puskesmas

Abstract - Health development at the first level in the Kuta Alam District of Banda Aceh City is carried out by the Puskesmas in accordance with Law Number 36 of 2009 concerning Health and Aceh Qanun Number 4 of 2010 concerning Health. This research is to find out the responsibilities and the implementation of the Puskesmas in the Health Care of Pesantren Community in Integrated Dayah Inshafuddin, Kuta Alam Subdistrict, Banda Aceh City, connected with Law and Qanun. This research uses a descriptive-analytical method with a normative juridical approach. The results showed the responsibility of the Puskesmas in health care was an institutional responsibility or position, because the duties and authorities carried out by the Puskesmas were the mandate of the Law and Qanun and the implementation of the Puskesmas responsibilities in carrying out promotive and preventive efforts had not succeeded in integrating various health efforts including efforts curative and rehabilitative policies are not yet detailed.

Keywords : Legal Responsibility, Health Care, Puskesmas

\section{A. PENDAHULUAN}

Undang-Undang Dasar 1945 Pasal

28 D ayat (1) berbunyi: Setiap orang berhak atas pengakuan, jaminan, perlindungan dan kepastian hukum yang adil serta perlakuan yang sama dihadapan hukum. Pasal $28 \mathrm{G}$ ayat (1) berbunyi: Setiap orang berhak atas perlindungan diri pribadi, keluarga, kehormatan, 
Habibi, Tanggung Jawab Puskesmas Dalam Pemeliharaan Kesehatan Masyarakat Pesantren Dihubungkan...

martabat, dan harta benda yang dibawah kekuasaannya, serta berhak atas rasa aman dan perlindungan dari ancaman ketakutan untuk berbuat atau tidak berbuat sesuatu yang merupakan hak asasi.

Undang-Undang Dasar 1945 pasal $28 \mathrm{H}$ menyatakan bahwa: Setiap orang berhak hidup sejahtera lahir dan batin, bertempat tinggal, dan mendapatkan lingkungan hidup baik dan sehat serta berhak memperoleh pelayanan kesehatan.

Dalam Undang-Undang Nomor 36 Tahun 2009 Tentang Kesehatan ditegaskan bahwa setiap orang berhak atas kesehatan disertai hak untuk mendapatkan informasi dan edukasi tentang kesehatan yang seimbang dan bertanggung jawab.

Peraturan Menteri Kesehatan Nomor 75 Tahun 2014 Tentang Pusat Kesehatan Masyarakat dalam menyelenggarakan fungsinya sebagaimana dimaksud dalam Pasal 5 huruf a, Puskesmas berwenang untuk (c) melaksanakan komunikasi, informasi, edukasi, dan pemberdayaan dalam bidang kesehatan.

Kesehatan merupakan hal terpenting yang diperlukan oleh tubuh manusia. Upaya peningkatan kualitas hidup manusia di bidang kesehatan merupakan suatu usaha yang sangat luas dan menyeluruh, usaha tersebut meliputi peningkatan kesehatan masyarakat baik fisik maupun non fisik, di dalam sistem kesehatan nasional disebutkan bahwa kesehatan menyangkut semua segi kehidupan yang ruang lingkup dan jangkauannya sangat luas dan kompleks (Nasution, 2013).

Upaya untuk meningkatkan derajat kesehatan masyarakat yang setinggitingginya dilaksanakan berdasarkan prinsip nondiskriminatif, partisipatif, perlindungan dan berkelanjutan yang sangat penting yang artinya bagi pembentukan sumber daya manusia, peningkatan ketahanan dan daya saing bangsa serta pembangunan nasional (Wibowo, 2014).

Perkembangan pelayanan kesehatan di Indonesia tidak lepas dari sejarah kehidupan bangsa Indonesia, pelayanan kesehatan masyarakat dikembangkan sejalan dengan tanggung jawab pemerintah dalam rangka melindungi masyarakat Indonesia dari gangguan kesehatan karena kesehatan adalah hak asasi manusia dan tercantum dalam Undang-Undang Dasar 1945 (Wibowo, 2014).

Upaya pemerintah dalam pembangunan kesehatan yaitu dengan mewujudkan masyarakat yang sehat 
Habibi, Tanggung Jawab Puskesmas Dalam Pemeliharaan Kesehatan Masyarakat Pesantren Dihubungkan...

mandiri dan berkeadilan, maka salah satu program pelayanan kesehatan yang saat ini menjadi prioritas adalah program jaminan kesehatan nasional, program jaminan kesehatan nasional adalah suatu program pemerintah dan masyarakat dengan tujuan memberikan kepastian jaminan kesehatan yang menyeluruh bagi setiap rakyat Indonesia agar penduduk Indonesia dapat hidup sehat, produktif dan sejahtera (Wibowo, 2014).

Dalam pelaksanaan Jaminan Kesehatan Nasional, Puskesmas sebagai Pemberi Pelayanan Kesehatan (PPK) tingkat pertama milik pemerintah daerah menjadi ujung tombak pelayanan kesehatan yang sangat penting karena merupakan fasilitas pelayanan kesehatan dasar yang berperan sebagai gate keeper atau kontak pertama kepada masyarakat, dan penakis rujukan sesuai dengan standar pelayanan medic (Indarwati, 2018). Puskesmas memiliki peran sebagai gerbang pertama yang diharapkan bisa memberikan pelayanan kesehatan kepada masyarakat secara komprehensif, tidak hanya melakukan pelayanan kepada perseorangan tetapi juga kepada masyarakat yang lebih luas. Upaya Kesehatan Masyarakat (UKM) menjadi tugas utama Puskesmas yang berfokus kepada upaya pencegahan dan promosi kesehatan masyarakat.

Menurut Peraturan Menteri Kesehatan Nomor 75 Tahun 2014 Tentang Pusat Kesehatan Masyarakat Puskesmas adalah fasilitas pelayanan kesehatan yang menyelenggarakan upaya kesehatan masyarakat dan upaya kesehatan perseorangan tingkat pertama, dengan lebih mengutamakan upaya promotif dan preventif, untuk mencapai derajat kesehatan masyarakat yang setinggitingginya di wilayah kerjanya. Secara fungsional, peran Puskesmas adalah sebagai pusat penggerak pembangunan berwawasan kesehatan, pusat pemberdayaan masyarakat, pusat pelayanan kesehatan strata satu, dan meliputi pelayanan kesehatan perseorangan serta masyarakat (Indarwati, 2018).

Pesantren yang merupakan salah satu wilayah kerja Puskesmas tentu harus memperoleh upaya kesehatan, saat ini Puskesmas sudah merata hampir di seluruh Indonesia, dan setiap kecamatan telah memiliki minimal satu Puskesmas. Jumlah Puskesmas pada tahun 2013 mencapai 9.655 buah $(3,89$ per 100.000 penduduk) (Rachmat, 2018). Puskesmas memberikan kontribusi yang sangat 
Habibi, Tanggung Jawab Puskesmas Dalam Pemeliharaan Kesehatan Masyarakat Pesantren Dihubungkan...

berarti untuk meningkatkan derajat kesehatan masyarakat.

Upaya kesehatan bagi masyarakat di Pesantren berupa upaya promotif dan preventif. Sesuai dengan Peraturan Menteri Kesehatan Nomor 75 Tahun 2014 Tentang Pusat Kesehatan Masyarakat dalam Pasal 36 ayat 2 huruf (e) bahwa upaya kesehatan masyarakat meliputi pelayanan pencegahan dan pengendalian penyakit. Kemudian Pemerintah Aceh melalui Qanun Aceh Nomor 4 Tahun 2010 Tentang Kesehatan Pasal 49 ayat 2 huruf (h) menegaskan bahwa Puskesmas dalam melaksanakan fungsinya, mempunyai tugas melakukan pencegahan dan penanganan penyakit menular dan tidak menular.

Pesantren dan santri merupakan elemen penting dalam kehidupan bernegara dan aset bagi kemajuan bangsa. Menteri Riset, Teknologi, dan Pendidikan Tinggi (Menristekdikti) Mohamad Nasir mengatakan Pesantren sebagai pihak yang telah turut berjuang memerdekakan bangsa, tentunya tidak rela jika NKRI diganggu melalui cara apapun. Nasir mengajak pesantren dan para santri di dalamnya terlibat aktif menjadi penggerak perdamaian di Indonesia dan turut mencegah tumbuhnya radikalisme di tengah masyarakat. Nasir juga mengatakan Pondok pesantren adalah tulang punggung untuk menciptakan kedamaian Indonesia (Nursalikah, tt). Dengan demikian, Pesantren sebagai elemen penting dan aset kemajuan bangsa maka harus diperhatikan masalah penyakit yang terdapat didalamnya.

Ada beberapa masalah penyakit di pondok pesantren yang telah menjadi ciri khas santri di Indonesia. Penyakit kulit merupakan salah satu penyakit yang masih menjadi masalah kesehatan masyarakat Indonesia. Menurut data Depkes RI prevalensi penyakit kulit diseluruh Indonesia ditahun 2012 adalah 8,46\% kemudian meningkat ditahun 2013 sebesar 9\% dan skabies menduduki urutan ketiga dari 12 penyakit kulit yang tersering (Balitbangkes RI, 2013). Sebanyak 14 provinsi mempunyai prevalensi penyakit kulit diatas prevalensi nasional, yaitu Nanggroe Aceh Darussalam, Sumatera Barat, Bengkulu, Bangka Belitung, DKI Jakarta, Jawa Barat, Jawa Tengah, DI Yogyakarta, Nusa Tenggara Timur, Kalimantan Tengah, Kalimantan Selatan, Sulawesi Tengah, dan Gorontalo (Balitbangkes RI, 2013).

Prevalensi skabies yang tinggi umumnya ditemukan dilingkungan 
Habibi, Tanggung Jawab Puskesmas Dalam Pemeliharaan Kesehatan Masyarakat Pesantren Dihubungkan...

dengan kepadatan penghuni dan kontak interpersonal tinggi seperti penjara, panti asuhan, dan pondok pesantren (Ridho, 2019). Tempat-tempat yang memiliki kepadatan tinggi, beresiko tinggi untuk terjadinya penularan skabies terutama asrama dan pesantren (Ridho, 2019).

Penyakit kutu budug skabies adalah penyakit kulit menular yang disebabkan oleh tungau Sarcoptes scabie var. hominis. Kutu Sarcoptes scabiei bukanlah serangga dari golongan insekta melainkan tungau dari Familia Sarcoptidae yang memiliki 4 pasang kaki (bukan tiga pasang seperti kelurga insekta) sehingga lebih dekat dengan keluarga sengkenit. Kutu ini ditularkan dengan hubungan kontak langsung pada kulit termasuk ketika berhubungan seks. Masih diragukan apakah kutu skabies dapat ditularkan melalui pakaian atau tilam, selimut atau sprei seperti pada kutu kepala dan kutu yang lain (Natadisastra, 2009).

Insiden dan prevalensi skabies masih sangat tinggi di Indonesia terutama pada lingkungan masyarakat pesantren. Hal ini tercermin dari penelitian Khotimah (2013) di Pondok Pesantren AlBahroniyyah Ngemplak Demak sebesar 36,3\%, di Pondok Pesantren di Kabupaten Pasuruan mencapai 66,70\%, bahkan di Pondok Pesantren Lamongan mencapai 73,3\% (Putri dkk, 2017). Sedangkan penelitian Ratnasari tahun 2014 prevalensi skabies di Pesantren X Jakarta Timur adalah 51,6\% (Ratnasari \& Sungkar, 2014). Hasil tersebut menunjukkan bahwa kejadian skabies masih sering dilingkungan pesantren (Hilma\& Ghazali, 2014).

Indonesia sebagai Negara dengan jumlah penduduk muslim terbanyak didunia, terdapat 28.961 pondok pesantren yang terdiri dari 15.057 (52\%) pondok pesantren salafi/ salafiah (tradisional), dan 13.904 (48\%) pondok pesantren khalafi/ khalafiah (modern) (Emis Pendis, 2015) dengan prevalensi skabies cukup tinggi (Ratnasari \& Sungkar, 2014).

Melihat Provinsi Aceh yang terdapat 1.222 pondok pesantren terdiri dari 673 pondok pesantren salafi/ salafiah (tradisional), dan 549 pondok pesantren khalafi/ khalafiah (modern) (Ratnasari \& Sungkar, 2014). Di Aceh tingkat kejadian skabies mencapai 40,78\% (Sutejo, Rosyidi, \& Zaelany, 2017).

Dayah Terpadu Inshafuddin merupakan salah satu Pondok Pesantren yang berada dibawah tanggung jawab bina wilayah UPTD Puskesmas Kecamatan Kuta Alam, Kota Banda 
Habibi, Tanggung Jawab Puskesmas Dalam Pemeliharaan Kesehatan Masyarakat Pesantren Dihubungkan...

Aceh. Dari hasil studi pendahuluan yang dilakukan oleh peneliti di Dayah Terpadu Inshafuddin pada hari senin tanggal 21 januari 2019, melalui metode wawancara dan observasi pada 10 santri yang diambil secara acak dari jumlah 550 santri di pesantren tersebut, didapatkan $40 \%$ atau 4 dari 10 santri yang terkena skabies. Sedangkan terdapat $60 \%$ atau 6 dari 10 santri yang tidak terkena skabies. Berdasarkan pemaparan santri, masalah kesehatan santri di pesantren sangat jarang mendapat perhatian yang baik dari warga pondok pesantren itu sendiri maupun masyarakat dan juga pemerintah.

Anggota Bagian Pangasuhan Asrama Ustadz Bobby M. Agam Wijaya mengatakan bahwa walaupun di Pesantren tersebut terdapat Unit Kesehatan Dayah (UKD) namun tidak memberikan pelayanan yang baik dalam upaya penyembuhan skabies. Penyakit yang di derita oleh para santri tersebut dapat mengganggu aktivitas mereka seperti beribadah dan belajar di pondok pesantren.

Penyelenggara pelayanan kesehatan dalam hal ini Puskesmas memiliki tanggung jawab terhadap pelayanan kesehatan masyarakat Pesantren sesuai dengan peraturan perundang-undangan, mengenai tanggung jawab yaitu suatu keadaan dimana seseorang wajib menanggung segala perbuatannya bila terjadi hal yang tidak diinginkan boleh dituntut, dipersilahkan atau diperkarakan (Siswati, 2013).

Dengan adanya permasalahan tersebut maka peneliti tertarik untuk melalukan penelitian mengenai Tanggung Jawab Puskesmas Dalam Pemeliharaan Kesehatan Masyarakat Pesantren Dihubungkan Dengan Undang-Undang Nomor 36 Tahun 2009 Tentang Kesehatan Dan Qanun Aceh Nomor 4 Tahun 2010 Tentang Kesehatan.

Berdasarkan latar belakang diatas, maka idetifikasi masalah adalah sebagai berikut :

1. Bagaimana Tanggung Jawab Puskesmas Dalam Pemeliharaan Kesehatan Masyarakat Pesantren Dihubungkan Dengan UndangUndang Nomor 36 Tahun 2009 Tentang Kesehatan dan Qanun Aceh Nomor 4 Tahun 2010 Tentang Kesehatan?

2. Bagaimana Implementasi Tanggung Jawab Puskesmas Dalam Pemeliharaan Kesehatan Masyarakat Pesantren di Dayah Terpadu Inshafuddin Kota Banda Aceh Dihubungkan Dengan UndangUndang Nomor 36 Tahun 2009 
Habibi, Tanggung Jawab Puskesmas Dalam Pemeliharaan Kesehatan Masyarakat Pesantren Dihubungkan...

Tentang Kesehatan dan Qanun Aceh Nomor 4 Tahun 2010 Tentang Kesehatan?

\section{B. PEMBAHASAN}

Dayah Terpadu Inshafuddin adalah lembaga pendidikan Islam yang bernaung di bawah Yayasan Pembina Inshafuddin yang memiliki visi dan misi dalam kegiatan kependidikan yaitu:

"Melaksanakan pembelajaran dan bimbingan dengan efektif dan efesien sehingga pelajar dapat berkembang secara optimal, cerdas, berakhlak mulia, memiliki kreatifitas untuk membangun diri dan lingkungan dalam rangka mengabdi kepada Allah SWT".

"Mampu mengaplikasikan ilmunya dalam kehidupan sehari-hari untuk menuju masyarakat madani berlandaskan Al-Qur'an dan Hadits yang bermazhab kepada Imam Syafi'ie dalam Faham Ahlussunnah Waljama'ah”.

Angka kesakitan (mordibitas) merupakan salah satu indikator dalam menilai derajat kesehatan suatu masyarakat. Untuk menurunkan angka kesakitan perlu upaya pengendalian penyakit, angka kesakitan berupa insiden maupun prevalensi dari suatu penyakit.

Penelitian dilakukan dengan wawancara bebas dimana peneliti tidak menggunakan pedoman wawancara yang telah tersusun secara sistematis. Data penelitian yang diambil berbentuk wawancara dengan mengambil sampel berdasarkan sumber data dengan pertimbangan bahwa sampel adalah orang yang sangat mengetahui tentang adanya kejadian skabies/ bekas penderita skabies di Dayah Terpadu Inshafuddin.

Penyakit skabies sering muncul sebagai Kejadian Luar Biasa (KLB) dengan angka kesakitan relatif tinggi. Jumlah kasus skabies di Dayah Terpadu Inshafuddin selama setahun akhir sebanyak 32 kasus (laki-laki 18 kasus dan perempuan 14 kasus). Cakupan penanganan kasus skabies belum maksimal, masih banyak terjadinya kasus skabies yang belum mendapatkan pelayanan yang memadai di Dayah Terpadu Inshafuddin.

Beberapa aspek yang mempengaruhi tingkat kesakitan kejadian skabies di Pondok Pesantren Dayah Terpadu Inshafuddin diantaranya adalah personal hygine, fasilitas kesehatan dan Upaya Kesehatan.

a. Personal Hygiene

Di Dayah Terpadu Inshafuddin untuk aspek personal hygiene (kebersihan diri) masih menunjukkan kurang. Kebersihan diri sangat berkaitan dengan pakaian, 
tempat tidur yang digunakan sehari-hari.

Kejadian skabies ditemukan di Dayah Terpadu Inshafuddin karena santri gemar sekali bertukar baju, pinjam meminjam pakaian, handuk, sarung bantal dan bantal serta kasurnya kepada temantemannya.

b. Fasilitas Kesehatan

Salah satu faktor yang mempengaruhi angka terjadinya skabies di Dayah Terpadu Inshafuddin adalah tidak adanya pelaksanaan kegiatan promosi dan preventif kesehatan secara berkesinambungan dan terus menerus oleh Puskesmas sebagai wilayah kerjanya.

c. Upaya Puskesmas dalam melakukan fungsi pelayanan kesehatan

Tabel 1.1

Upaya Promotif kesehatan pada kasus skabies (Hasil penelitian diolah)

\begin{tabular}{|c|c|c|c|}
\hline No. & Program & $\begin{array}{c}\text { Realisasi Hasil } \\
\text { Program/ } 6 \\
\text { bulan }\end{array}$ & $\begin{array}{l}\text { Lokasi } \\
\text { Pelaksanaan }\end{array}$ \\
\hline 1. & $\begin{array}{l}\text { Penyuluhan } \\
\text { kebersihan } \\
\text { dan sanitasi } \\
\text { lingkungan }\end{array}$ & $\begin{array}{l}\text { 1. Dilaksanakan } \\
1 \text { kali di } \\
\text { Pesantren } \\
\text { dengan } \\
\text { peserta } \\
\text { seluruh santri } \\
\text { 2. Narasumber } \\
\text { dari } \\
\text { Puskesmas } \\
\text { 3. Pelaksanaan } \\
\text { kegiatan } \\
\text { dibagi dalam } \\
\text { 2 angkatan } \\
\text { sehingga } \\
\text { kegiatan } \\
\text { dilakukan } \\
\text { selama } 2 \text { hari }\end{array}$ & $\begin{array}{l}\text { Aula Dayah } \\
\text { Terpadu } \\
\text { Inshafuddin }\end{array}$ \\
\hline 2. & $\begin{array}{l}\text { Penyebarlua } \\
\text { san } \\
\text { informasi } \\
\text { tentang }\end{array}$ & $\begin{array}{l}\text { 1. Dilaksanakan } \\
1 \text { kali di } \\
\text { Pesantren } \\
\text { dengan }\end{array}$ & $\begin{array}{l}\text { Ruangan } \\
\text { Belajar } \\
\text { SMA Dayah } \\
\text { Terpadu }\end{array}$ \\
\hline
\end{tabular}

\begin{tabular}{|c|c|c|c|}
\hline & penyakit & $\begin{array}{l}\text { peserta } 30 \\
\text { orang } \\
\text { 2. Narasumber } \\
\text { dari } \\
\text { Puskesmas } \\
\end{array}$ & Inshafuddin \\
\hline 3. & $\begin{array}{l}\text { Deteksi dini } \\
\text { terhadap } \\
\text { penyakit } \\
\text { skabies } \\
\text { termasuk } \\
\text { pengetahuan } \\
\text { dasar } \\
\text { tentang } \\
\text { penyakit } \\
\text { skabies dan } \\
\text { tindakan } \\
\text { pertolongan } \\
\text { pertama }\end{array}$ & $\begin{array}{l}\text { 1. Dilaksanakan } \\
1 \text { kali di } \\
\text { Pesantren } \\
\text { dengan semua } \\
\text { pihak pondok } \\
\text { pesantren } \\
\text { 2. Narasumber } \\
\text { dari } \\
\text { Puskesmas }\end{array}$ & $\begin{array}{l}\text { Lingkungan } \\
\text { Dayah } \\
\text { Terpadu } \\
\text { Inshafuddin }\end{array}$ \\
\hline 4. & $\begin{array}{l}\text { Keluarga } \\
\text { berencana }\end{array}$ & 1. - & \\
\hline 5. & $\begin{array}{l}\text { Kesehatan } \\
\text { remaja }\end{array}$ & 1. - & \\
\hline 6. & $\begin{array}{l}\text { Kesehatan } \\
\text { ibu dan } \\
\text { anak }\end{array}$ & 1. - & \\
\hline 7. & $\begin{array}{l}\text { Kesehatan } \\
\text { usia lanjut }\end{array}$ & 1. - & \\
\hline 8. & $\begin{array}{l}\text { Penyalahgu } \\
\text { naan } \\
\text { narkotika, } \\
\text { psikotropika } \\
\text { dan bahan } \\
\text { berbahaya } \\
\text { lainnya }\end{array}$ & $\begin{array}{l}\text { 1. Dilaksanakan } \\
1 \text { kali di } \\
\text { Pesantren } \\
\text { dengan } \\
\text { peserta } 30 \\
\text { orang } \\
\text { 2. Narasumber } \\
\text { dari Badan } \\
\text { Narkotika } \\
\text { Nasional } \\
\text { (BNN) Kota } \\
\text { Banda Aceh } \\
\text { dan Dinas } \\
\text { Kesehetan } \\
\text { Kota Banda } \\
\text { Aceh }\end{array}$ & $\begin{array}{l}\text { Aula Dayah } \\
\text { Terpadu } \\
\text { Inshafuddin }\end{array}$ \\
\hline
\end{tabular}

Tabel 1.2

Upaya Preventif kesehatan pada kasus skabies (Hasil penelitian diolah)

\begin{tabular}{|c|c|c|c|}
\hline No. & Program & $\begin{array}{c}\text { Realisasi Hasil } \\
\text { Program/ } 6 \\
\text { bulan }\end{array}$ & $\begin{array}{l}\text { Lokasi } \\
\text { Pelaksanaan }\end{array}$ \\
\hline 1. & $\begin{array}{l}\text { Upaya } \\
\text { pencegahan } \\
\text { langsung } \\
\text { terhadap } \\
\text { sumber } \\
\text { penularan } \\
\text { penyakit }\end{array}$ & $\begin{array}{l}\text { 1. Dilaksanakan } \\
1 \text { kali di } \\
\text { Pesantren } \\
\text { dengan } \\
\text { peserta } \\
\text { seluruh santri } \\
\text { 2. Narasumber } \\
\text { dari } \\
\text { Puskesmas }\end{array}$ & $\begin{array}{l}\text { Aula Dayah } \\
\text { Terpadu } \\
\text { Inshafuddin }\end{array}$ \\
\hline
\end{tabular}




\begin{tabular}{|c|c|c|}
\hline 2. & $\begin{array}{l}\text { Pemberian } \\
\text { imunisasi } \\
\text { lengkap }\end{array}$ & 1. - \\
\hline 3. & $\begin{array}{l}\text { Upaya } \\
\text { pendekatan } \\
\text { melalui } \\
\text { Perilaku } \\
\text { Hidup } \\
\text { Bersih dan } \\
\text { Sehat } \\
\text { (PHBS) }\end{array}$ & $\begin{array}{l}\text { 1. Dilaksanakan } \\
1 \text { kali di } \\
\text { Pesantren } \\
\text { dengan } \\
\text { Peserta Santri } \\
\text { Tingkat SMA } \\
\text { 2. Narasumber } \\
\text { dari } \\
\text { Puskesmas }\end{array}$ \\
\hline
\end{tabular}

Tabel 1.3

Upaya Kuratif kesehatan pada kasus skabies (Hasil penelitian diolah)

\begin{tabular}{|c|l|l|l|}
\hline No. & Program & $\begin{array}{c}\text { Realisasi Hasil } \\
\text { Program/ 6 } \\
\text { bulan }\end{array}$ & $\begin{array}{l}\text { Lokasi } \\
\text { Pelaksanaan }\end{array}$ \\
\hline 1. & $\begin{array}{l}\text { Upaya } \\
\text { mengenal } \\
\text { dan } \\
\text { mengetahui } \\
\text { jenis } \\
\text { penyakit } \\
\text { pada tingkat } \\
\text { awal serta } \\
\text { mengadakan } \\
\text { pengobatan } \\
\text { yang tepat } \\
\text { dan segera }\end{array}$ & $1 .-$ & - \\
\hline
\end{tabular}

Tabel 1.4

Upaya Rehabilitatif kesehatan pada kasus skabies (Hasil penelitian diolah)

\begin{tabular}{|c|c|c|c|}
\hline No. & Program & $\begin{array}{c}\text { Realisasi Hasil } \\
\text { Program/ } 6 \\
\text { bulan }\end{array}$ & $\begin{array}{l}\text { Lokasi } \\
\text { Pelaksanaan }\end{array}$ \\
\hline 1. & $\begin{array}{l}\text { Upaya } \\
\text { rehabilitasi } \\
\text { fisik }\end{array}$ & 1. - & - \\
\hline 2. & $\begin{array}{l}\text { Upaya } \\
\text { rehabilitasi } \\
\text { mental }\end{array}$ & $1 . \quad-$ & - \\
\hline 3. & $\begin{array}{l}\text { Upaya } \\
\text { rehabilitasi } \\
\text { sosial } \\
\text { vokasional }\end{array}$ & 1. - & - \\
\hline 4. & $\begin{array}{l}\text { Upaya } \\
\text { rehabilitasi } \\
\text { aesthetis }\end{array}$ & $1 . \quad-$ & - \\
\hline
\end{tabular}

Tanggung Jawab Puskesmas Dalam Pemeliharaan Kesehatan Masyarakat Pesantren Berdasarkan Undang-
Undang Nomor 36 Tahun 2009 Tentang Kesehatan dan Qanun Aceh Nomor 4 Tahun 2010 Tentang Kesehatan

Tanggung jawab adalah suatu akibat dari kebebasan seseorang tentang perbuatannya atau tentang apa yang telah dilakukan (Notoatmodjo, 2018). Tanggung jawab selalu terkandung pengertian "penyebab" dari perbuatan namun demikian, tanggung jawab tidak selalu langsung oleh orang yang oleh orang sebagai pelaku, hal ini disebabkan karena yang bertanggung jawab adalah orang yang mempunyai kehendak bebas (Notoatmodjo, 2018). Sedangkan pelayanan kesehatan adalah segala bentuk kegiatan yang ditujukan untuk meningkatkan derajat suatu masyarakat yang mencakup kegiatan penyuluhan, peningkatan kesehatan, pencegahan penyakit, penyembuhan dan pemulihan kesehatan yang diselenggarakan secara terpadu dan berkesinambungan yang secara sinergis berhasil guna dan berdaya guna sehingga tercapai derajat kesehatan masyarakat yang setinggi-tingginya (Adisasmito, $\mathrm{tt}$ ).

Tanggung jawab Puskesmas dalam pemeliharaan kesehatan pesantren merupakan tanggung jawab institusional atau jabatan, dikarenakan tugas dan 
Habibi, Tanggung Jawab Puskesmas Dalam Pemeliharaan Kesehatan Masyarakat Pesantren Dihubungkan...

kewenangan yang dilaksanakan oleh puskesmas adalah amanat UndangUndang dan Qanun Aceh, maka tindakannya tersebut dipertanggung jawabkan secara jabatan atau pertanggungjawaban institusional.

Upaya pelayanan kesehatan yang diberikan oleh Puskesmas meliputi promotif, preventif, kuratif dan rehabilitatif. Upaya promotif dan preventif bertujuan untuk meningkatkan pengetahuan tentang hak-hak pasian, meningkatkan kesadaran masyarakat pesantren terhadap pentingnya kebersihan serta upaya memperoleh akses pelayanan kesehatan yang diperlukan. Upaya kuratif bertujuan untuk pengobatan, sedangkan upaya rehabilitatif bertujuan untuk pemulihan.

1. Tanggung jawab hukum pada upaya promotif

Negara mempunyai kewajiban untuk memberikan pelayan kesehatan kepada masyarakat oleh tenaga kesehatan yang memiliki keahlian dan kewenangan yang ditujukan untuk memelihara dan meningkatkan kesehatan serta mencegah penyakit suatu kelompok dan masyarakat.

Upaya promotif pelayanan kesehatan dengan promosi kesehatan terhadap kelompok orang sehat agar mereka mampu meningkatkan kesehatannya karena apabila kelompok yang sehat ini sedikit mendapatkan pengetahuan tentang kesehatan maka kelompok sakit akan meningkat. Peningkatan pemahaman mengenai skabies diharapakan dapat meningkatkan derajat kesehatan masyarakat pesantren.

Upaya promotif Puskesmas berdasarkan Pasal 62 Ayat 1 UndangUdang Nomor 36 Tahun 2009 Tentang Kesehatan yaitu kegiatan penyuluhan, penyebarluasan informasi, atau kegiatan lain untuk menujang tercapainya hidup sehat. Pasal 56 Ayat 2 Qanun Aceh Nomor 4 Tahun 2010 Tentang Kesehatan bahwa upaya promotif Puskesmas meliputi penyuluhan kebersihan dan sanitasi, penyakit menular dan tidak menular, deteksi dini terhadap penyakit berbasis lingkungan terutama pada anakanak termasuk pengetahuan dasar tentang penyakit dan tindakan pertolongan pertama, keluarga berencana, kesehatan remaja, kesehatan ibu dan anak, kesehatan usia lanjut, penyalahgunaan narkotika, psikotropika dan bahan berbahaya lainnya.

Salah satu upaya kesehatan yang diberikan adalah upaya promotif, pentingnya upaya promotif dalam meningkatkan derajat kesehatan masyarakat merupakan amanat undang- 
Habibi, Tanggung Jawab Puskesmas Dalam Pemeliharaan Kesehatan Masyarakat Pesantren Dihubungkan...

undang yang sudah semestinya dilaksanakan dengan sebaik mungkin, pentingnya pelayanan promotif dalam bidang promosi kesehatan melalui kegiatan pemberian informasi kesehatan (promosi kesehatan), termasuk pengembangan desa siaga pada masyarakat desa/ kelurahan, khusus bidang kesehatan juga memprioritaskan program kesehatan di setiap wilayah melalui upaya promotif dan preventif.

2. Tanggung jawab hukum pada upaya preventif

Upaya pelayanan kesehatan yang bersifat preventif adalah suatu kegiatan pencegahan terhadap suatu masalah kesehatan atau upaya preventif dapat dilaksanakan dengan kegiatan promosi kesehatan itu pada kelompok yang memiliki atau beresiko tinggi dengan meningkatnya upaya kegiatan preventif dan menyadarkan masyarakat pesantren akan pentingnya pecegahan maka membantu menurunkan angka kejadian skabies dan meningkatkan derajat kesehatan.

Pasal 62 ayat 2 Undang-Undang Nomor 36 Tahun 2009 tentang Kesehatan menjelaskan tentang pencegahan penyakit dengan segala bentuk upaya yang dilakukan oleh Pemerintah Daerah dan atau masyarakat untuk menghindari atau mengurangi resiko yang timbul akibat penyakit sedangkan pada Pasal 57 Qanun Aceh Nomor 4 Tahun 2010 Tentang Kesehatan menegaskan bahwa Satuan Kerja Perangkat Aceh (SKPA) harus melakukan upaya pencegahan penyakit yang mencakup upaya pencegahan langsung terhadap sumber penularan penyakit, pemberian imunisasi lengkap, dan upaya pendekatan melalui Perilaku Hidup Bersih dan Sehat (PHBS).

3. Tanggung jawab hukum pada upaya kuratif

Pelayanan kesehatan pada upaya kuratif berdasarkan Undang-undang Nomor 36 Tahun 2009 tentang Kesehatan adalah suatu kegiatan dan atau serangkaian kegiatan pengobatan yang ditujukan untuk penyembuhan penyakit, pengurangan penderitaan akibat penyakit, pengendalian penyakit dan pengendalian kecacatan agar kualitas penderita dapat terjadi.

Upaya pengobatan terhadap pasien penderita skabies dilakukan oleh tenaga medis berdasarkan ilmu kedokteran dalam hal ini pengobatan dasar sebelum merujuk ke lanjutan, upaya kuratif di lakukan pengobatan dasar sesuai dengan standar prosedur. Upaya perbaikan kesehatan lingkungan juga diperlukan 
Habibi, Tanggung Jawab Puskesmas Dalam Pemeliharaan Kesehatan Masyarakat Pesantren Dihubungkan...

untuk meunjang keberhasilan pengobatan.

Pada Qanun Aceh tentang Kesehatan tidak terdapat kebijakan mengenai upaya kuratif. Berdasarkan persoalan tersebut maka perlu adanya kebijakan terperinci mengenai upaya kuratif terhadap pemeliharaan kesehatan.

4. Tanggung jawab hukum pada upaya rehabilitatif

Upaya rehabilitatif adalah kegiatan dan atau serangkaian kegiatan yang mengembalikan bekas penderita ke dalam masyarakat sehingga dapat berfungsi lagi sebagai anggota masyarakat yang berguna untuk dirinya dan masyarakat semaksimal mungkin sesuai dengan kemampuannya. Upaya rehabilitatif juga merupakan upaya pemulihan kesehatan bagi penderita penyakit yang dirawat dirumah, maupun terhadap kelompokkelompok tertentu yang menderita penyakit yang sama khususnya skabies.

Pasal 63 Ayat 1 Undang-Undang Nomor 36 Tahun 2009 Tentang Kesehatan menyebutkan penyembuhan penyakit dan pemulihan kesehatan pasien yang tadinya sakit menjadi sehat dan mengembalikan fungsi tubuh akibat penyakit badan atau akibat cacat.

Namun pada Qanun Aceh tidak mengatur tentang upaya rehabilitatif pada
Puskesmas sehingga perlu adanya kebijakan terperinci mengenai upaya pelayanan rehabilitatif.

5. Permasalahan tanggung jawab hukum pada pemeliharaan kesehatan Puskesmas

Terjadi hubungan antara tenaga kesehatan di puskesmas dan pasien dalam hal ini masyarakat pesantren selain hubungan medik terbentuk pola hubungan hukum pada hubungan medik tenaga kesehatan dan masyarakat pesantren adalah hubungan yang tidak seimbang, dalam arti masyarakat pesantren penderita skabies adalah orang sakit yang awam dan tenaga kesehatan orang yang sehat dan lebih tahu tentang medis namun dalam hukum terdapat hubungan hukum yang seimbang yakni hak pasien menjadi kewajiban tenaga kesehatan dan sebaliknya hak tenaga kesehatan menjadi kewajiban bagi pasien dan keduanya merupakan subjek hukum.

Sedangkan hubungan diantara penyelenggara pelayanan kesehatan dalam hal ini puskesmas dan pasien tergantung dari pada hubungan antara tenaga kesehatan dan pasien, kemudian bilamana terjadi kerugian yang diderita oleh pasien maka pasien bisa menuntut ganti rugi dan pasien juga harus mencari 
Habibi, Tanggung Jawab Puskesmas Dalam Pemeliharaan Kesehatan Masyarakat Pesantren Dihubungkan...

tahu dahulu di mana unsur kesalahannya yang menimbulkan kerugian.

\section{Implementasi Tanggung Jawab}

Puskesmas dalam Pemeliharaan

Kesehatan Masyarakat Pesantren di

Dayah Terpadu Inshafuddin

Berdasarkan Undang-Undang Nomor

36 Tahun 2009 Tentang Kesehatan dan Qanun Aceh Tentang Kesehatan

1. Tanggung jawab hukum upaya promotif dan preventif pada Puskesmas di Dayah Terpadu Inshafuddin Kecamatan Kuta Alam

Berdasarkan hasil wawancara dengan bagian keasramaan pondok pesantren, penulis mendapatkan hasil yang kurang sesuai dengan kebijakan, pada puskesmas kecamatan kuta alam agak jarang melakukan upaya-upaya promotif dengan konsep promosi kesehatan.

Dilihat di lapangan hasil dari wawancara dan observasi pada pondok pesantren masih banyak terdapat keluhan berupa tidak efektifnya pemberian upaya promosi kesehatan. Kurangya pemahaman mengenai penyakit skabies membuat masyarakat pesantren yang kebingungan akan cara pencegahan dan penyembuhannya. Salah satunya karena kurangnya peran pihak Puskesmas untuk mengedukasi masyarakat pesantren mengenai hal ini. Tidak hanya itu, tidak sadarnya masyarakat pesantren akan kebiasaan buruk yang dilakukan maka semakin menambah buruk kondisi. Anggapan bahwa sanitasi yang ada sudah baik merupakan faktor yang paling besar dalam terjangkitnya penyakit skabies.

Bila dilihat pada Pasal 62 Ayat 2 Undang-Undang Nomor 36 Tahun 2009 berkaitan dengan Pasal 59 Ayat 2 Qanun Aceh Nomor 4 Tahun 2010 Tentang Kesehatan yaitu Puskesmas wajib melaksanakan program pemerintah di bidang kesehatan, maka oleh karena itu Puskesmas memiliki tanggung jawab hukum dalam melaksanakan upaya Preventif yang dilaksanakan sesuai dengan peraturan perundang-undangan.

2. Tanggung jawab hukum upaya kuratif dan rehabilitatif pada Puskesmas di Dayah Terpadu Inshafuddin Kecamatan Kuta Alam Pelaksanaan upaya kuratif pada Puskesmas di Dayah Terpadu Inshafuddin memiliki gambaran hasil yang bagus berdasarkan wawancara terhadap masyarakat pesantren secara umum. Namun demikian, banyak ditemukan perilaku santri yang minim terhadap personal hygiene sehingga tidak mengetahui pola hidup yang sehat dan beranggapan pelayanan kesehatan sudah gampang dicapai sehingga ketika sakit 
Habibi, Tanggung Jawab Puskesmas Dalam Pemeliharaan Kesehatan Masyarakat Pesantren Dihubungkan...

bisa langsung berobat, dari kajian ini maka dalam rangka meningkatkan derajat kesehatan dirasa perlu promosi kesehatan pada tingkat kuratif.

Berdasarkan wawancara dengan masyarakat pesantren memperoleh hasil bahwa tenaga medis sedikit sekali memberikan penjelasan ketika pasien berobat dikarenakan sedikit sekali waktu yang dibutuhkan atau tidak adanya waktu untuk tenaga medis dalam menjelaskan kepada pasien. Promosi kesehatan pada tingkat kuratif mempunyai tujuan agar penderita skabies mampu mencegah penyakit tersebut supaya tidak menjadi lebih parah.

\section{PENUTUP}

\section{Kesimpulan}

a. Tanggung jawab Puskesmas dalam pemeliharaan kesehatan pesantren merupakan tanggung jawab institusional atau jabatan, dikarenakan tugas dan kewenangan yang dilaksanakan oleh puskesmas adalah amanat UndangUndang dan Qanun Aceh, maka tindakannya tersebut dipertanggung jawabkan secara jabatan atau pertanggungjawaban institusional. Tanggung jawab hukum puskesmas dalam pemeliharaan kesehatan masyarakat pesantren pada upaya promotif dan preventif yang merupakan upaya yang diutamakan pada wilayah kerjanya berdasarakan Pasal 62 Ayat (1) dan (2) Undang-Undang Nomor 36 Tahun 2009 Tentang Kesehatan juncto Pasal 49 Ayat (2) Huruf H Qanun Aceh Tentang Kesehatan bahwa puskesmas dalam melaksanakan fungsinya mempunyai tugas melakukan pencegahan dan penanganan penyakit menular dan tidak menular melalui upaya promotif berupa kegiatan penyuluhan kebersihan dan sanitasi, dan penyebarluasan informasi, sedangkan upaya preventif berupa kegiatan pencegahan penyakit yang mencakup upaya pencegahan langsung terhadap sumber penularan penyakit dan upaya pendekatan melalui Perilaku Hidup Bersih dan Sehat (PHBS).

b. Implementasi Tanggung Jawab Hukum pada Puskesmas Kecamatan Kuta Alam Kota Banda Aceh pada upaya promotif dan preventif berdasarkan Pasal 62 Ayat (1) dan (2) Undang-Undang Nomor 36 Tahun 2009 Tentang Kesehatan juncto Pasal 49 Ayat (2) Huruf H Qanun Aceh Tentang Kesehatan yaitu Puskesmas dalam melaksanakan fungsinya mempunyai tugas melakukan pencegahan dan penanganan penyakit menular dan tidak menular, puskesmas sebagai pembina di wilayah kerjanya 
Habibi, Tanggung Jawab Puskesmas Dalam Pemeliharaan Kesehatan Masyarakat Pesantren Dihubungkan...

memiliki tanggung jawab hukum dalam melaksanakan upaya promotif dan preventif yang merupakan upaya yang lebih diutamakan. Upaya-upaya promotif dan preventif yang telah dilakukan belum berhasil memadukan berbagai upaya kesehatan yang ada di masyarakat pesantren termasuk pada upaya kuratif dan rehabilitatif belum ada kebijakan secara terperinci.

\section{Saran}

a. Memerlukan penambahan aturan lebih spesifik pada Qanun Aceh tentang fungsi puskesmas dalam mengatur upaya promotif, preventif, kuratif dan rehabilitatif terkait pembinaan kesehataan secara terus menerus dan berkesinambungan agar terwujud kesehatan optimal.

b. Diperlukannya kerjasama antar fasilitas kesehatan untuk terlaksananya pemeliharaan kesehatan secara menyeluruh dan merata di wilayah kerjanya dan memberdayakan masyarakat pesantren di bidang kesehatan melalui Upaya Kesehatan Bersumberdaya Masyarakat (UKBM) berupa Pos Kesehatan Pesantren (Poskestren).

\section{DAFTAR PUSTAKA}

Adik Wibowo dan Tim, Kesehatan Masyarakat di Indonesia
(Konsep, Aplikasi, dan Tantangan), Rajawali Pers, Jakarta, 2014.

Bahder Johan Nasution, Hukum Kesehatan Pertanggungjawaban Dokter, Rineka Cipta, Jakarta, 2013.

Djaenudin Natadisastra. Parasitologi kedokteran: ditinjau dari organ tubuh yang diserang. Editor, Djaenudin Natadisastra, Ridad Agoes. Jakarta: EGC, 2009.

Endang Kusuma A, Transaksi Teurapeutik dalam Upaya Pelayanan Medis di Rumah Sakit, PT. Citra Aditya Bakti, Bandung, 2009.

R. Hapsara Habib Rachmat, Penguatan Upaya Kesehatan Masyarakat dan Pemberdayaan Masyarakat Bidang Kehatan di Indonesia, UGM PRESS, Yogyakarta, 2018.

Soekidjo Notoatmodjo, Etika dan Hukum Kesehatan, Rineka Cipta, Jakarta, 2018.

Sri Siswati, Etika dan Hukum Kesehatan dalam Perspektif UndangUndang Kesehatan, Rajawali Pers, Jakarta, 2013.

Wiku Adisasmito, Kebijakan Standar Pelayanan Medik dan Diagnosis Related Group (DRG), Kelayakan Penerapannya di Indonesia, Jakarta, Fak. Kesehatan Masyarakat, UI.

\section{Disertasi, Tesis dan Skripsi}

Putri et al., MEDICINE (Medis Cilik Excellent) di Pondok Pesantren Nurul Jadid sebagai Upaya 
Habibi, Tanggung Jawab Puskesmas Dalam Pemeliharaan Kesehatan Masyarakat Pesantren Dihubungkan...

Pencegahan Skabies (Kudis). Program Studi Farmasi Universitas UM: Malang. 2017.

Zarkasyi Ridho, Hubungan Antara Perilaku Hidup Bersih Sehat dan Tingkat Pendidikan dengan Kejadian Skabies di Pesantren Nurul Ummah Kotagede Yogyakarta, Skripsi, Universitas Muhammadiyah Surakarta, Surakarta, 2019.

\section{Jurnal dan Majalah}

Hilma, U.D. \& Ghazali, L., FaktorFaktor Yang Mempengaruhi Kejadian Skabies Di Pondok Pesantren Mlangi Nogotirto Gamping Sleman Yogyakarta. Jurnal Kedokteran dan Kesehatan Indonesia, Vol 6, No 3, 2014.

Ratnasari, A. F. \& Sungkar, S., Prevalensi Skabies dan Faktorfaktor yang Berhubungan di Pesantren X, Jakarta Timur, eJournal Kedokteran Indonesia, Vol 2, No 1, 2014.

Retno Indarwati, https: ners.unair.ac.id $>$ materikuliah $>$ Pus kesmas

Sutejo, I.R., Rosyidi, V.A., \& Zaelany, A.I., Prevalensi, Karakteristik dan Faktor-Faktor yang Berhubungan dengan Penyakit Skabies di Pesantren Nurul Qamain Kabupaten Jember. Jurnal Pustaka Kesehatan, Vol 5, No 1, Januari 2017.

\section{Peraturan Perundang-Undangan}

Pasal 1 Angka 1 Undang-Undang Nomor 39 Tahun 1999, Tentang Hak Asasi Manusia (HAM).
Peraturan Menteri Kesehatan Nomor 75 Tahun 2014 Tentang Pusat Kesehatan Masyarakat.

Qanun Aceh Nomor 4 Tahun 2010 Tentang Kesehatan.

Undang-Undang Dasar RI tahun 1945 Pasal 28 D.

Undang-Undang Dasar RI tahun 1945 Pasal $28 \mathrm{G}$.

Undang-Undang Dasar RI tahun 1945 Pasal $28 \mathrm{H}$.

Undang-Undang Nomor 36 Tahun 2009 tentang Kesehatan.

\section{Internet}

Ani Nursalikah, Menristekdikti: Pesantren Aset Pemersatu Bangsa https://www.republika.co.id/berita /dunia-islam/islamnusantara/17/05/24/oqfox6366menristekdikti-pesantren-asetpemersatu-bangsa

Badan Penelitian dan Pengembangan Kesehatan Republik Indonesia, 2013.

Education Management Information System, Pendidikan Islam/ EMISPENDIS, Kemenag, 2014/ 2015 . 
Habibi, Tanggung Jawab Puskesmas Dalam Pemeliharaan Kesehatan Masyarakat Pesantren Dihubungkan... 